\title{
Digital readiness index assessment towards smart port development
}

\author{
Robert Philipp ${ }^{1,2}$ (D) \\ Published online: 26 May 2020 \\ (c) The Author(s) 2020
}

\begin{abstract}
Digital technologies receive more and more attention in the maritime transport sector. Large ports such as Rotterdam or Antwerp are already heavily investing in digital databased technologies and thus, continue to rely on a sustainable expansion of these advanced technologies that promise security, process optimization and sustainability. Conversely, especially smaller ports have no or limited knowledge on what Industry 4.0, IoT and Blockchain are and what potentials they may have. Nevertheless, without the inclusion of small and medium-sized ports, the innovative idea towards a smart port development stays unachievable. Related to this, there exist a lack of concepts and models for measuring the digital performance of ports. Without such tools, it is impossible to audit the digital status of ports and to derive a concrete strategic roadmap for the digital transformation of ports. Accordingly, in this study, the research questions will be investigated, how the digital performance of ports can be assessed, and which strategic recommendations can be derived for ports regarding a sustainable development towards a smart port. Building upon the received qualitative data that were gathered through an online survey and IT based expert interviews, a digital readiness index for ports is applied in case of five selected seaports. The results will show that building upon the benchmarking and indexing of the ports, the current strategic positioning of the ports becomes apparent. Through this, the respective strategic recommendations for a sustainable development towards a smart port can be derived in accordance to each port classification.
\end{abstract}

Keywords Digitalisation · Smart Port · Port Performance Measurement · Port Performance Indicators · Digital Readiness Index $\cdot$ Maturity Model

\section{Introduction}

Since recent years, the interest in digital technologies and their progress in various industrial and service sectors increases. Due to the promising value proposition, the growing cross-sectoral distribution and the value creation potential of digital technologies, they also receive more and more recognition in the maritime industrial and transport sector (Philipp et al. 2020a, 2018). In the European context, especially large ports-the so-called core ports of the "Trans-

\footnotetext{
Availability of data and material R. Philipp collected and analysed the used and presented primary data that was gathered in the frame of the project "Connect2SmallPorts", which is part-financed by the European Regional Development Fund (INTERREG VA South Baltic programme).

Robert Philipp

robert.philipp@hs-wismar.de

1 Hochschule Wismar, University of Applied Sciences: Technology, Business and Design, Philipp-Müller-Str. 14, 23966 Wismar, Germany

2 TALTECH University, Ehitajate tee 5, 19086 Tallinn, Estonia
}

European Transport Network" (TEN-T)—such as Rotterdam or Antwerp are already familiar with digital databased technologies like Blockchain or Internet of Things (IoT) and thus, continue to rely on a sustainable expansion of these advanced technologies that promise security, process optimization and sustainability. They are developing rapidly and merge into huge digital networks and platforms. By doing so, they connect and converge physical and digital worlds (i.e. machines, devices and humans). The main goal of such novel digital technologies is to optimize economic performance and energy demand, to reduce the consumption of resources and waste and to better qualify the service portfolio. Indeed, seaports rely on large transport and logistics companies when it comes to the development and implementation of innovative technology applications. Since major transport companies like Maersk are already heavily investing in digital technologies that are regarded as the enablers for the digital transformation in the context of Industry and Logistics 4.0, it is important that also ports-including in particular small and medium-sized ports-take the opportunity to apply these novel technological solutions in order to integrate themselves in a sustain- 
able way into global supply chains. Otherwise, in the longterm, this will result in uncatchable competitive disadvantages. Accordingly, dealing with new digital technologies is crucial for both, large core ports and small and mediumsized ports (Philipp et al. 2018).

Especially, when it comes to the novel visionary idea of a smart port development, which currently receives a growing attention in practice and research landscape, the investigation with digitalisation and related novel technologies becomes more and more important. The idea of a smart port development is associated with an innovative endeavour where the focus is centred on improving the competitiveness of the port and facilitating entrepreneurial collaboration between different port stakeholders to achieve horizontal and vertical integration of supply chains (Douaioui et al. 2018). Hence, in such a scenario the port will be completely connected via a communications network and fully integrated with its environment (i.e. all stakeholders of the industry) as well as other ports and logistics actors around the globe. Accordingly, without the inclusion of small and medium-sized ports, this innovative idea stays unachievable. However, so far, this idea of a smart port is still a vision. Nevertheless, it is expected that especially the usage and implementation of the newly arisen digital technologies will contribute substantial to the development towards a smart ports.

Yet, especially smaller ports have no or limited knowledge on what Industry 4.0, IoT and Blockchain are and what potentials they may bring. Hence, smaller ports often do not know about the already existing wide range of ICT solutions and current trends that allow optimising the infrastructure and transport services (Philipp et al. 2018). Next to this, in research and practice there exist a lack of concepts and models for measuring the digital performance of ports. Without such tools, it is impossible to audit the digital status of ports and to derive a concrete strategic roadmap for the digital transformation towards a sustainable smart port development (Philipp et al. 2020b).

In order to close these research gaps, this present study aims to apply a tool to assess the digital readiness of ports, and building upon this to derive a concrete strategic graduation that sets up the roadmap for the digital transformation towards a sustainable smart port development. Accordingly, in the framework of this study, the research questions will be investigated, how the digital performance of ports-regardless their size and cargo preference-can be assessed, and in a subsequent step, which strategic recommendations can be derived for ports regarding a sustainable development towards a smart port; or with other words: how to conceptualise the roadmap for the digital transformation of ports towards a smart port development?

The research was conducted in the frame of the still ongoing EU-project "Connect2SmallPorts", which is imple- mented in the cross-border cooperation platform INTERREG South Baltic Programme 2014-2020. Among other things, the EU-project focus on improving cross-border connectivity for a functional blue and green transport area, with the objective to enhance the quality and environmental sustainability of transport services in South Baltic Sea Region.

The paper is structured as follow: In the second chapter, the needed theoretical background is drawn by referring to "Port Performance Measurement", "Digital and Industry 4.0 Readiness Indexes and Maturity Models" and the aspired vision of a "Smart Port". Afterwards, the used method is set out. Subsequently, the results are highlighted, which is followed by a discussion regarding the developed model. The paper rounds up with a conclusion.

\section{Theory}

\subsection{Port performance measurement}

Port performance measurement (PPM) is widely accepted and performed in practice and research landscape. Principally, PPM concepts incorporate so-called Key Performance Indicators (KPIs), whereby due to their defined target-oriented purpose these KPIs are often labelled as Port Performance Indicators (PPIs) (e.g. de Langen et al. 2007; Talley 1994). One of the oldest, but most common frameworks for PPM is the one from the "United Nation Conference on Trade and Development" (UNCTAD) from 1976 (UNCTAD 1976), which is often concerned as the origin source in the course of newly developed PPI concepts. However, over a half of century most PPM concepts had been developed in order to measure especially the performance of container ports and container transport logistics (CTL) (e.g. Tongzon 1995; Talley 2006; Cullinane et al. 2005; Wang et al. 2003; etc.). Therefore, it can be noted that past research efforts focalised mainly on operative performance measurement in larger ports, who handle containers (Twenty-foot Equivalent Unit-TEU) as primary cargo type-that specifically in the European context are often associated with core ports in the sense of the TEN-T (Philipp et al. 2018).

Due to the arising interests in digitalisation, recent PPM concepts exhibit novel indicators like IT system, Databases, Networks, Integrated EDI for communication, Integrated IT to share data, etc. (Ha et al. 2019), but still exclusively had been elaborated and applied for container ports. Next to this target group limitation, there exist no PPI framework that was created for the purpose to measure the digital performance of ports (Philipp et al. 2020b). Accordingly, among other things, the existing PPM concepts in theory and practice do not refer to the wide range of innovative technologies 
that nowadays are regarded as the enablers for the digital transformation towards a smart port development (ibid.).

\subsection{Digital and industry 4.0 readiness indexes and maturity models}

In order to overcome the existing research gap of missing digital performance measurement instruments for ports, the big variety of developed digitalisation and Industry 4.0 readiness indexes and maturity models in recent years represents a promising research trend and suitable reference point. Thereby, Industry 4.0-the forth-industrial revolution-is the allegory of the digitalisation idea in the industrial and in particular manufacturing sector, and thus, is regarded as the digital transformation process of the industry, which becomes enabled and driven by the fast technology development (Horvat et al. 2018; Rajnai and Kocsis 2018). Digital and Industry 4.0 readiness indexes are well established on macro level, where they are applied to measure and compare the digital performance of different nations-for instance: Networked Readiness Index (NRI) from the World Economic Forum (2016), Industry 4.0 Readiness Index from the consultancy company Roland Berger (2020), Digitisation Index (DiGiX) from BBVA Research (n.d.). In contrast to this, of particular interest are especially the added numerous digital and Industry 4.0 readiness indexes and maturity models that have been developed during the last years for analysing and measuring the digital performance and Industry 4.0 readiness of companies (micro level). According to Rajnai and Kocsis (2018), digital and "Industry 4.0 readiness index assessments, and maturity models can support the management at benchmarking, and setting up a roadmap for the digital transformation of their company" by auditing the current digitalisation status of benchmarked firms. Hence, transferred to the port sector, the question emerges, why there is a lack of applied digitalisation/Industry 4.0 readiness index or maturity models, respectively, in order to set up the roadmap for the digital transformation of ports towards smart port development.

\subsection{Smart port}

The term smart port currently receives a growing attention in practice and different research studies. The idea of a smart port development is associated with an innovative endeavour where the focus is centred on improving the competitiveness of the port and facilitating entrepreneurial collaboration between different port stakeholders to achieve horizontal and vertical integration of supply chains (Douaioui et al. 2018). Building upon the findings from Yang et al. (2018), a smart port may be defined as a fully automated port where all devices are connected via IoT. Furthermore, a network of smart sensors and actuators, wireless devices as well as data centres make up the key infrastructure of the smart port, which allows the port operators or authorities, respectively, to provide more efficiently traditional and new services, whereby the major drivers in the smart port development are productivity and efficiency increases. Hence, various different technological applications are used to gather the needed data in order to enable the digital transformation towards a smart port development (ibid.). According to the Whitepaper from Gardeitchik et al. (2017) as well as smart port value creation model from Deloitte (2017) based on Porter's Value Chain Analysis (Porter 1985), the development of ports towards a smart port takes place in five stages:

- Stage 0: where the port has no automation at all,

- Stage 1: includes individual automation,

- Stage 2: where all port-involved stakeholders aim to integrate their systems to achieve better communication,

- Stage 3: the port and the hinterland players are connected through one single digital environment,

- Stage 4: smart port stage, connects each port with its environment and all ports globally with each other.

\section{Method}

Generally, most of the digital and Industry 4.0 readiness indexes and maturity models on micro level that had been introduced in theory and practice target to evaluate the performance of manufacturing firms, which is deeply rooted in the fact that they are the main target group in the context of Industry 4.0. In particular, the overall logistics sector is relatively unaffected by digital and Industry 4.0 readiness indexes and maturity models. Thus, Decker and Blaschczok (2018) claimed in their study that they had been the first, who elaborated a digital readiness analysis in the logistics sector-in detail: digital readiness index for Logistics Service Providers (LSPs). The research from Philipp et al. (2020b) confirmed this. Furthermore, they proposed on a theoretical basis a digital readiness index for ports in the frame of their literature review article, by what the identified and related research gap of missing digital performance instruments for ports was closed. This digital readiness index for ports is called DRIP and was developed on the basis of identified, analysed and triangulated literature findings from the research landscape and practice about PPIs as well as digital and Industry 4.0 readiness indexes and maturity models plus practical findings that had been elaborated in the course of the EU-project Connect2SmallPorts. Accordingly, it is the first of its kind and allows to audit the digital performance of ports, e.g. in the frame of a potential self-assessment or benchmarking. Since, so far, the developed DRIP by Philipp et al. (2020b) was not applied and tested, it was used in the course of 
Table 1 Digital Auditing Tool for Ports_-DRIP (based on: Philipp et al. 2020b)

\begin{tabular}{|c|c|c|c|c|}
\hline Dimension & $\begin{array}{l}\text { Weight } \\
(\%)\end{array}$ & No & Indicator & Scale applied \\
\hline \multirow[t]{4}{*}{ Management } & \multirow[t]{4}{*}{20} & 1 & $\begin{array}{l}\text { Digitalisation Strategy (incl. Gov- } \\
\text { ernance, Standards, Cultural Guide- } \\
\text { lines, Progress Indicators, etc.) }\end{array}$ & \multirow[t]{3}{*}{$\begin{array}{l}\text { Implementation status: 1) Not existing, 2) Pilot initiatives are } \\
\text { planned, 3) In development phase, 4) Formulated and defined, 5) Is } \\
\text { in implementation phase, 6) Is implemented }\end{array}$} \\
\hline & & 2 & Digital Business Model & \\
\hline & & 3 & Innovation Cooperation & \\
\hline & & 4 & Investments in Digitalisation & \multirow{2}{*}{$\begin{array}{l}\text { Share of digital investments (x), proportion of employees with an IT } \\
\text { educational background }(x): 1) x \leq 10 \%, 2) 10 \%<x \leq 20 \% \text {, } \\
\text { 3) } 20 \%<x \leq 30 \% \text {, 4) } 30 \%<x \leq 40 \%, 5) 40 \%<x \leq 50 \%, 6) x>50 \%\end{array}$} \\
\hline \multirow[t]{3}{*}{ Capital } & \multirow[t]{3}{*}{20} & 5 & IT Knowledge \& Skills (Education)* & \\
\hline & & 6 & IT Capabilities* & \multirow{8}{*}{$\begin{array}{l}\text { Level of capabilities, scope of training, adequacy of integrated } \\
\text { communications, accuracy of information regarding status of } \\
\text { shipment, provision of on-time of information, compatibility of } \\
\text { operating system, degree of process adaptability in meeting } \\
\text { customer requirements, degree of IT security: 1) Very bad, 2) Bad, } \\
\text { 3) Rather bad, 4) Rather good, 5) Good, 6) Very good }\end{array}$} \\
\hline & & 7 & $\begin{array}{l}\text { IT Training \& Education Opportuni- } \\
\text { ties* }\end{array}$ & \\
\hline \multirow[t]{6}{*}{$\begin{array}{l}\text { Functionality } \\
\text { (IT) }\end{array}$} & \multirow[t]{6}{*}{25} & 8 & $\begin{array}{l}\text { Integrated Communications Infras- } \\
\text { tructure* }\end{array}$ & \\
\hline & & 9 & $\begin{array}{l}\text { Information regarding Status of Ship- } \\
\text { ment* }\end{array}$ & \\
\hline & & 10 & On-time of Information* & \\
\hline & & 11 & Operating System* & \\
\hline & & 12 & Processes* & \\
\hline & & 13 & Security & \\
\hline \multirow[t]{17}{*}{ Technology } & \multirow[t]{17}{*}{30} & 14 & Smart ERP System & \multirow{17}{*}{$\begin{array}{l}\text { Degree of usage: 1) Technology/System not known, 2) No use case } \\
\text { available, 3) Usage not planned, 4) Usage is planned, 5) In specific } \\
\text { projects already implemented, 6) Comprehensive usage }\end{array}$} \\
\hline & & 15 & Smart WMS System & \\
\hline & & 16 & $\begin{array}{l}\text { Smart PCS System (incl. Electronic } \\
\text { SCM System) }\end{array}$ & \\
\hline & & 17 & Web-based Communication Platform & \\
\hline & & 18 & Mobile Data Access for Employees & \\
\hline & & 19 & Mobile Data Access for Customers & \\
\hline & & 20 & $\begin{array}{l}\text { IoT (incl. Machine-to-Machine-Com- } \\
\text { munication) }\end{array}$ & \\
\hline & & 21 & Cloud Computing (SaaS, PaaS, IaaS) & \\
\hline & & 22 & $\begin{array}{l}\text { Localisation Technologies (GPS, } \\
\text { RFID, etc.) }\end{array}$ & \\
\hline & & 23 & $\begin{array}{l}\text { Sensors (Humidity, Temperature, } \\
\text { etc.) }\end{array}$ & \\
\hline & & 24 & $\begin{array}{l}\text { Big Data \& Predictive Analytics (e.g. } \\
\text { for Maintenance, etc.) }\end{array}$ & \\
\hline & & 25 & Blockchain (incl. Smart Contracts) & \\
\hline & & 26 & Artificial Intelligence (AI) & \\
\hline & & 27 & Robotics & \\
\hline & & 28 & Drones (Air, Land, Water) & \\
\hline & & 29 & $\begin{array}{l}\text { Autonomous Solutions (Terminals, } \\
\text { Cranes, Vehicles)_CPS (Cyber- } \\
\text { Physical Systems) }\end{array}$ & \\
\hline & & 30 & $\begin{array}{l}\text { Digital Twinning, Augmented \& } \\
\text { Virtual Reality (incl. Simulation) }\end{array}$ & \\
\hline \multirow[t]{8}{*}{ Information } & \multirow[t]{8}{*}{5} & 31 & Personal Network & \multirow{8}{*}{$\begin{array}{l}\text { Degree of information procurement: 1) Very low, 2) Low, 3) Rather } \\
\text { low, 4) Rather high, 5) High, 6) Very high }\end{array}$} \\
\hline & & 32 & Printed Media & \\
\hline & & 33 & Internet & \\
\hline & & 34 & Social Media Resources & \\
\hline & & 35 & Fairs & \\
\hline & & 36 & Conferences & \\
\hline & & 37 & Associations (e.g. Consultancy, etc.) & \\
\hline & & 38 & Scientific Institutions & \\
\hline
\end{tabular}

* PPI 
the present study. As shown in Table 1, the DRIP consists of five dimensions and 38 related indicators, whereby some of them represent PPIs. As mentioned by Philipp et al. (2020b), the indicated weighting factors in the DRIP model represent the importance of each dimension, which had been determined during expert interviews with project experts, whereby all 38 indicators are equally weighted in each dimension.

The following assessment presented in this paper bases on primary data analysis according to the received qualitative data. ${ }^{1}$ The preceding empirical data collection activities for the present study were conducted between the 01st of December 2019 and 26th of January 2020, which represents a total data collection duration of 8 weeks. Since the digital auditing procedures took place in the setting of the still ongoing EU-project Connect2SmallPorts, which is part-financed by the European Regional Development Fund (INTERREG VA South Baltic programme), the main target group of this current study was also defined by small and medium-sized seaports of the South Baltic Sea Region (SBSR)-i.e. eligible catchment area of the INTERREG VA South Baltic programme. Thereby, medium-sized seaports are associated with comprehensive ports in the sense of the TEN-T, whereby small-sized ports do not belong to the TEN-T. Nevertheless, from empirical data collection activities, large seaports (i.e. core ports in the sense of the TEN-T) were not precluded, which enables in the further discourse of this paper the comparison with a best practice example as well as allows to prove the applicability and application friendliness of the investigated and applied DRIP-regardless of port size and cargo preference. Accordingly, due to the underlying EU-project Connect2SmallPorts that is implemented in the INTERREG VA South Baltic programme, the geographical scope of data collections activities mainly focused on the adjacent SBSR countries (namely: Germany, Lithuania, Poland, Denmark and Sweden). Nevertheless, the geographical scope of data collections activities was not limited to this region, which resulted in the frame of the present study into the incorporation of one Spanish port: Valencia. The reason for the inclusion of Valencia seaport can be seen in the fact that this core port according to the TEN-T shows the highest digital readiness among all ports, who participated in the online survey during the abovementioned study period. Moreover, since the usage of the DRIP model enables a benchmarking of ports, Valencia seaport was selected as the best-practice

\footnotetext{
1 Only in case of the two indicators "Investments in Digitalisation" and "IT Knowledge \& Skills (Education)" also quantitative data was gathered. Accordingly, the majority (36 from 38 indicators) of elaborated data represents qualitative data.
}

example in the course of the following analysis-i.e. due to its forerunner position in case of digitalisation. ${ }^{2}$

Therefore, the empirical data collection was at the beginning exclusively online-based, whereby the invitation to the online survey "Digital Auditing in Small Ports" reached the target group via E-Mails, which was ensured by the author of the present study. Accordingly, the following key advantages could be perceived through the online-based data collection: (1) ensuring that the questionnaire was carried out anonymously, (2) exclusion of influencing the respondents due to the survey situation, and (3) facilitation of respondents' time-based flexibility (Döring and Bortz 2016; Diekmann 2007; O'Leary 2017; Schnell et al. 2004). Vice versa, possible disadvantages of an online-based survey could be reduced or largely ruled out, since, for example, in order to prevent misuse in the form of multiple participation, the inclusion of cookies was conducted (Schnell et al. 2004), and comprehension problems-which can be discussed or clarified in an oral or telephone survey-could be limited or eliminated, as the topic and its essential contents were explained on the first page of the online survey. Against this background, it can be assumed that the ports, who participated in the online survey, are familiar with the topic (Philipp et al. 2019a).

Next to this, the participants of the online survey were informed on the first page of the online survey about the topic, aim and purpose of the survey and the EU-project Connect2SmallPorts as well as the subsequent data processing activities. Moreover, port representatives had been informed that participation in the survey is voluntary. At the end, these and further given information resulted in the option for the potential participants to agree on the indicated consent form and provided information, or not. All these information and explanations as well as the declaration of consent were showcased and implemented in order to be in line and to show compliance with the EU data protection regulation (ibid.).

However, in order to measure the digital performance of ports and thus, to demonstrate the applicability and application friendliness of the investigated and used DRIP model, as well as in a supplementary step, to assess the strategic graduation towards a smart port development, an evidencebased approach has been chosen and applied in the present study. Hence, by taking into account the indicated research objectives, the cases of five European seaports had been selected for the present study. Thus, these selected cases of five European seaports were compared in the following ac-

\footnotetext{
2 According to the respective figures from 2018, Valencia was worldwide on the 29th place in the container segment (Lloyd 2019). This once more highlights the sustainability of using Valencia seaport as a best-practice example for small and medium-sized ports in the current study.
} 
cording to Yin (2017). To ensure this and highlight the particularity and complexity of the single case evidences (Stake 1995), further IT-based structured and semi-structured expert interviews had been conducted with top-level managers from selected five seaports, which mainly had been carried out in January 2020. The interviews lasted about $1 \mathrm{~h}$. The results from the online survey, together with the findings from the expert interviews ensured to gain profound insights on the current digitalisation status of the investigated ports. Thereby, especially the expert interviews uncovered the backgrounds and reasons for the indicated answered to the closed-ended questions in the online survey. However, more important was-in a supplementary step of the expert interviews-validation and subsequent verification of the strategic graduation model towards smart port development, which was developed and proposed by the author of the present study. Accordingly, interviews were recorded and transcribed. Hence, indicated recommendations and suggestions for improvements regarding proposed model were taken into account. Finally, these activities in the frame of the interview analysis according to Kvale (2008) and Miles and Huberman (1984) led to the presented strategic graduation model towards smart port development.

Next to the abovementioned reason for the inclusion of Valencia seaport as a best practice example in the frame of the benchmarking, the other four seaports (namely: Klaipeda (LT), Karlskrona (SE), Wismar and Stralsund (DE)) had been selected for the present study out of 33 audited ports $^{3}$, since they had been chosen by the Connect2SmallPorts project as so-called pilot cases. Furthermore, the author is presenting these selected case studies - that have been evaluated on digital readiness by applying the DRIP-with a specific focus on promoting of the developed strategic graduation model towards smart port development.

\section{Results}

In line with the DRIP matrix presented in Table 1, the following assessment of the seaports Valencia (ES), Klaipeda (LT), Karlskrona (SE), Wismar and Stralsund (DE) took place.

Thereby, the PPI "IT Capabilities" in the dimension "Human Capital" was further differentiated into the subindicators "IT infrastructure", "Automation technology",

\footnotetext{
33 ports have been audited, which complies with the set target indicator 30+ indexed ports in the EU-project Connect2SmallPorts. Nevertheless, the online survey will be open and regularly updated during and beyond project lifetime until the end of the year 2026. Thus, access to the questionnaire is granted for interested port representatives via the following link: https://ww2.unipark.de/uc/Connect2SmallPortsDRIP/.
}

"Data analytics", "Data security/communications security", "Development of/application of assistance systems", "Collaboration software", "Non-technical skills such as systems thinking and process understanding". Accordingly, the respective findings concerning the PPI "IT Capabilities", which are highlighted in Table 2 (here: aggregated results through the usage of the arithmetic mean), are showcased in detail in the following Table 3.

Building upon the maturity models from Gill and VanBoskirk (2016) as well as Gardeitchik et al. (2017), and the smart port value creation model from Deloitte (2017) based on Porter's Value Chain Analysis (Porter 1985) as well as results from the conducted expert interviews, the author of the present study proposes the following strategic graduation model towards smart port development in Table 4.

According to Table 2, the best performing port in the study is the Mediterranean seaport Valencia, since the digital readiness index assessment (DRIP) delivered the highest score or index with 5.195. Hence, Valencia seaport shows the highest digital readiness among all investigated cases. Therefore, in the present study, the Spanish seaport is the best-practice example in the course of the benchmarking. Valencia is classified as a core port according to the analogy of the TEN-T and thus, can be regarded as a large port. In 2019, the total cargo throughput amounted to ca. $80,000,000 t$, whereby the focus lies on container handling/traffic with about $77 \%$. In the same year, about 1,141,000 passengers passed through the seaport. Regarding the results per dimension according to Table 2 and 3, it can be noted that potential for improvements is observable in case of "Human Capital" (4.905) and "Technology" (4.941). Therefore, in order to become a small port, it can be recommended to strategically foster actions in these two areas. Vice versa, the digital performances regarding the dimensions "Management" (5.5) and "Functionality (IT)" (5.5) are almost on a very high level. According to Table 4, the port of Valencia with a DRIP score of 5.195 can be classified in this study as a "Developer port".

The seaport of Klaipeda ranks on the second place in this study (cf. Table 2), resulting from a DRIP score of 4.871. The Lithuanian port, which is located in the BSR, is also classified according to the TEN-T as a core port. In 2019, the total cargo throughput was about 48,000,000 t. The port of Klaipeda is a typical multi-purpose port, since about $20 \%$ of the total freight is attributable to "Liquid bulk goods", $35 \%$ to "Dry bulk goods", $18 \%$ to "Containers", $11 \%$ to "Ro-Ro mobile self-propelled units" and about $16 \%$ to "Others, not specified cargo". Moreover, in 2019 ca. 68,000 passengers transited the seaport. By taking into account the results per dimension from Table 2, it can be stated that concerning the dimension "Management" and to a certain extend also in case of the dimension "Technology", the seaport of Klaipeda is on a similar 
Table 2 Digital Readiness Index Assessment

\begin{tabular}{|c|c|c|c|c|c|c|c|}
\hline Dimension & Weight & Indicator & Valencia & Klaipeda & Karlskrona & Wismar & Stralsund \\
\hline \multirow[t]{4}{*}{ Management } & \multirow[t]{4}{*}{$20 \%$} & Digitalisation Strategy & 6 & 6 & 1 & 3 & 2 \\
\hline & & Digital Business Model & 6 & 6 & 2 & 2 & 2 \\
\hline & & Innovation Cooperation & 6 & 5 & 2 & 2 & 2 \\
\hline & & Investments in Digitalisation & 4 & 5 & 1 & 2 & 2 \\
\hline \multirow[t]{3}{*}{ Human Capital } & \multirow[t]{3}{*}{$20 \%$} & IT Knowledge \& Skills* & 5 & 5 & 2 & 1 & 2 \\
\hline & & IT Capabilities* & 4.714 & 4.286 & 3.286 & 3.714 & 5.000 \\
\hline & & $\begin{array}{l}\text { IT Training \& Education Opportuni- } \\
\text { ties* }\end{array}$ & 5 & 4 & 4 & 4 & 5 \\
\hline \multirow[t]{6}{*}{ Functionality (IT) } & \multirow[t]{6}{*}{$25 \%$} & $\begin{array}{l}\text { Integrated Communications Infras- } \\
\text { tructure* }\end{array}$ & 6 & 5 & 3 & 3 & 5 \\
\hline & & $\begin{array}{l}\text { Information regarding Status of Ship- } \\
\text { ment* }\end{array}$ & 6 & 5 & 3 & 4 & 5 \\
\hline & & On-time of Information* & 5 & 5 & 3 & 4 & 6 \\
\hline & & Operating System* & 5 & 4 & 4 & 5 & 5 \\
\hline & & Processes* & 5 & 6 & 3 & 4 & 4 \\
\hline & & Security & 6 & 4 & 4 & 4 & 5 \\
\hline \multirow[t]{17}{*}{ Technology } & \multirow[t]{17}{*}{$30 \%$} & Smart ERP System & 5 & 5 & 3 & 5 & 4 \\
\hline & & Smart WMS System & 5 & 5 & 3 & 5 & 4 \\
\hline & & Smart PCS System & 6 & 6 & 4 & 5 & 3 \\
\hline & & Web-based Communication Platform & 6 & 6 & 5 & 5 & 3 \\
\hline & & Mobile Data Access for Employees & 6 & 6 & 5 & 5 & 4 \\
\hline & & Mobile Data Access for Customers & 6 & 5 & 4 & 5 & 3 \\
\hline & & IoT (incl. M2M-Communication) & 5 & 5 & 4 & 4 & 3 \\
\hline & & Cloud Computing & 5 & 4 & 4 & 5 & 3 \\
\hline & & Localisation Technologies & 5 & 6 & 4 & 4 & 4 \\
\hline & & Sensors & 6 & 5 & 3 & 4 & 4 \\
\hline & & Big Data \& Predictive Analytics & 5 & 4 & 3 & 3 & 4 \\
\hline & & Blockchain & 4 & 4 & 4 & 4 & 3 \\
\hline & & Artificial Intelligence & 4 & 4 & 4 & 4 & 3 \\
\hline & & Robotics & 4 & 5 & 3 & 4 & 3 \\
\hline & & Drones & 4 & 4 & 4 & 4 & 4 \\
\hline & & Autonomous Solutions-CPS & 4 & 5 & 3 & 4 & 3 \\
\hline & & $\begin{array}{l}\text { Digital Twinning, Augmented \& Vir- } \\
\text { tual Reality }\end{array}$ & 4 & 4 & 4 & 4 & 3 \\
\hline \multirow[t]{8}{*}{ Information } & \multirow[t]{8}{*}{$5 \%$} & Personal Network & 4 & 4 & 4 & 4 & 5 \\
\hline & & Printed Media & 5 & 5 & 5 & 3 & 5 \\
\hline & & Internet & 6 & 5 & 5 & 4 & 6 \\
\hline & & Social Media Resources & 6 & 4 & 5 & 3 & 4 \\
\hline & & Fairs & 5 & 4 & 3 & 3 & 6 \\
\hline & & Conferences & 5 & 4 & 4 & 4 & 6 \\
\hline & & Associations & 5 & 4 & 4 & 3 & 4 \\
\hline & & Scientific Institutions & 5 & 4 & 3 & 4 & 5 \\
\hline \multirow{5}{*}{$\begin{array}{l}\text { Results per } \\
\text { Dimension- } \\
\text { arithmetic mean } \\
\text { (without } \\
\text { weighting factors) }\end{array}$} & & Management & 5.500 & 5.500 & 1.500 & 2.250 & 2.000 \\
\hline & & Human Capital & 4.905 & 4.429 & 3.095 & 2.905 & 4.000 \\
\hline & & Functionality (IT) & 5.500 & 4.833 & 3.333 & 4.000 & 5.000 \\
\hline & & Technology & 4.941 & 4.882 & 3.765 & 4.353 & 3.412 \\
\hline & & Information & 5.125 & 4.250 & 4.125 & 3.500 & 5.125 \\
\hline \multicolumn{3}{|l|}{ DRIP Score (Index) } & 5.195 & 4.871 & 3.088 & 3.512 & 3.730 \\
\hline
\end{tabular}

* PPI 
Table 3 IT Capability Assessment

\begin{tabular}{|c|c|c|c|c|c|c|}
\hline No & Sub-Indicator & Valencia & Klaipeda & Karlskrona & Wismar & Stralsund \\
\hline 6.1 & IT infrastructure & 4 & 5 & 4 & 5 & 5 \\
\hline 6.2 & Automation technology & 4 & 4 & 3 & 2 & 5 \\
\hline 6.3 & Data analytics & 5 & 5 & 3 & 2 & 6 \\
\hline 6.4 & Data security/communications security & 5 & 4 & 4 & 5 & 5 \\
\hline 6.5 & Development of/application of assistance systems & 6 & 4 & 3 & 3 & 4 \\
\hline 6.6 & Collaboration software & 5 & 4 & 3 & 5 & 5 \\
\hline 6.7 & $\begin{array}{l}\text { Non-technical skills such as systems thinking and } \\
\text { process understanding }\end{array}$ & 4 & 4 & 3 & 4 & 5 \\
\hline \multicolumn{2}{|c|}{ IT Capabilities (arithmetic mean) } & 4.714 & 4.286 & 3.286 & 3.714 & 5.000 \\
\hline
\end{tabular}

Table 4 Strategic Graduation towards Smart Port Development

\begin{tabular}{|c|c|c|c|}
\hline $\begin{array}{l}\text { Port } \\
\text { classifi- } \\
\text { cation }\end{array}$ & Characteristics & Strategy description & DRIP Score (x) \\
\hline $\begin{array}{l}\text { Smart } \\
\text { port }\end{array}$ & $\begin{array}{l}\text { The port is completely connected via a communications } \\
\text { network and fully integrated with its environment (i.e. all } \\
\text { stakeholders of the industry) as well as other ports and } \\
\text { logistics actors around the globe. Scheduling of the various } \\
\text { transport modes is optimised and real time cargo tracking } \\
\text { with all relevant players involved is enabled }\end{array}$ & $\begin{array}{l}\text { Merge the physical and digital worlds. Ensure } \\
\text { steady improvement by continuous development } \\
\text { of sustainable and innovative business cases }\end{array}$ & $5.5 \leq x \leq 6.0$ \\
\hline $\begin{array}{l}\text { Developer } \\
\text { port }\end{array}$ & $\begin{array}{l}\text { The port and the hinterland players are connected through } \\
\text { one single digital environment, the advantages of the pre- } \\
\text { vious stages are extended to even more stakeholders. Ad- } \\
\text { ditional advantages are expected in overall planning and } \\
\text { scheduling within the port and its hinterland. The port } \\
\text { targets on continuous improvement }\end{array}$ & $\begin{array}{l}\text { Usage of digitalisation to create competitive } \\
\text { advantage and maintain the competitive advan- } \\
\text { tage by targeting on sustainable integration and } \\
\text { ongoing enhancements. New businesses should } \\
\text { be generated and ecosystem partnerships must } \\
\text { expand }\end{array}$ & $4.5 \leq x<5.5$ \\
\hline $\begin{array}{l}\text { Adopter } \\
\text { port }\end{array}$ & $\begin{array}{l}\text { The port and immediately involved organisations (regu- } \\
\text { larly: authority, operator, customs, etc.) started to integrate } \\
\text { their (information) systems in order to achieve better com- } \\
\text { munication. Hence, a small single digital environment } \\
\text { will be created and several advantages such as better co- } \\
\text { ordination and reduction of waiting times for all means of } \\
\text { transportation can be achieved. The environment is per- } \\
\text { ceived }\end{array}$ & $\begin{array}{l}\text { Prioritisation of customer relationships depend- } \\
\text { ing on own processes and service structure. } \\
\text { Strategic decisions should be driven by analyt- } \\
\text { ics. Act on environmental changes and consider } \\
\text { them in decision making process. Overall new } \\
\text { business opportunities should be identifiable }\end{array}$ & $3.5 \leq x<4.5$ \\
\hline $\begin{array}{l}\text { Monitor } \\
\text { port }\end{array}$ & $\begin{array}{l}\text { Individual automations in the port might emerge. Port } \\
\text { authority, operator and related organisations in the near } \\
\text { proximity of the port maintain their own processes and } \\
\text { databases as well as started to digitalise them individu- } \\
\text { ally. Accordingly, information and relevant data is cap- } \\
\text { ture across specific nodes. The port environment is moni- } \\
\text { tored. Regarding the customers, a statistics driven policy is } \\
\text { driven }\end{array}$ & $\begin{array}{l}\text { Focus and improve adaptive capacities. Espe- } \\
\text { cially skills and knowledge of employees on all } \\
\text { hierarchical levels should be enhanced, whereby } \\
\text { outsourcing strategy for digital expertise rep- } \\
\text { resents a suitable alternative. Try to change } \\
\text { observer role (slightly) to a more pro-active role }\end{array}$ & $2.5 \leq x<3.5$ \\
\hline $\begin{array}{l}\text { Analog } \\
\text { port }\end{array}$ & $\begin{array}{l}\text { Automation do not exist. The port has no or less knowl- } \\
\text { edge about digitalisation and thus, do not know how to } \\
\text { change or is not willing. Furthermore, the port performs } \\
\text { usually the landlord functions. Regarding customers, the } \\
\text { first-come-first-serve policy is usually applied }\end{array}$ & $\begin{array}{l}\text { Change attitude by getting awareness of benefit } \\
\text { and added value that comes from a sustainable } \\
\text { digital development (i.e. digital transformation). } \\
\text { Start sensing and shaping }\end{array}$ & $1.0 \leq x<2.5$ \\
\hline
\end{tabular}

high level as the seaport of Valencia. However, a need for action is noticeable regarding all other dimensions ("Human Capital" = 4.429, "Functionality (IT)" = 4.833, "Information" $=4.25$ ). According to the assessed digital readiness index of 4.871 and with regard to Table 4, Klaipeda port may be classified as a "Developer port", too.

On the third place ranks the German seaport Stralsund, since the digital readiness assessment in Table 2 shows a score of 3.73. Stralsund in the BSR do not belongs to the TEN-T and thus, can be categorised as a small port. This is also noticeable according to the overall in- and outgoing cargo of about 2,000,000t in 2019, whereby the major focus lies on the handling of "Dry bulk goods" with ca. $80 \%$. Next to this, in 2019 , about 16,500 passengers passed through the BSR port. By analysing the results of Table 2, it becomes obvious that for the dimension "Infor- 
mation", the same result was achieved as the best practice example Valencia (both: 5.125). Also the result that refers to the dimension "Functionality (IT)" can be evaluated as sound (5.0). Moreover, it is a little bit surprising that the findings of Table 3 suggest that for the PPI "IT Capabilities", the seaport of Stralsund exhibits the greatest digital performance among all investigated ports in this study. Moreover, this highlighted peculiarity was also detectable in the frame of further indicators that are apparent in Table 2. Nevertheless, an urgent need for action is given concerning the dimension "Management" (2.0), "Technology" (3.412) and lastly "Human Capital" (4.0). However, the overall result of Stralsund with an index of 3.73 suggests that this port can be categorised as an "Adopter port" (cf. Table 2 and 4).

The other German seaport Wismar is on the fourth place in the current study with a digital readiness index of 3.512 (cf. Table 2). The seaport of Wismar is a comprehensive port according to the TEN-T and thus, may be regarded as a medium-sized port. In 2019, the overall cargo throughput was 6,091,976t. Thereby, about $91 \%$ are attributable to "Dry bulk goods". In contrast to this, only 4,445 passengers transited the BSR seaport in 2019. Compared to the best practice example (Valencia seaport), considerable backlog is observable throughout all dimensions ("Management" $=2.250$, "Human Capital" $=2.905$, "Functionality $($ IT $) "=4.0$, "Technology"= 4.353, "Information"=3.5) in the case of seaport of Wismar (cf. Table 2). Nevertheless, the overall DRIP score of 3.512 (cf. Table 2) suggests that Wismar seaport can be classified according to Table 4 only just as an "Adopter port".

On the last rank, the Swedish port Karlskrona achieved an overall digital readiness score of 3.088 (cf. Table 2). According to the TEN-T, Karlskrona is classified as a comprehensive port, too. However the medium-sized port handled in 2019 only ca. 450,000t of freight. Moreover, the shares are distributed with $44 \%$ to "Ro-Ro mobile selfpropelled units", $13 \%$ to "Ro-Ro mobile non self-propelled unit", $11 \%$ to "Containers" and 5\% to "Dry bulk goods". In addition, in 2019, about 700,000 passengers transited the seaport. Therefore, it can be noted that Karlskrona represents rather a ferry port, since the share of handled cargo is quite low. Need for action is visible among all dimensions that are indicated in Table 2 ("Management" $=1.5$, "Human Capital" $=3.095$, "Functionality (IT)" $=3.333$, "Technology"=3.765, "Information"=4.125). In sum, the achieved digital readiness index of 3.088 by the BSR seaport Karlskrona results-in accordance to Table 3-into the categorisation as a classical "Monitor port".

Lastly, the typical characteristics as well as the related current strategical positioning of each port and the concrete strategic recommendations-towards a smart port development- that apply for each port classification (i.e. "Analog port", "Monitor port", “Adopter port", "Developer port" and "Smart port"), dependent from the achieved score based on the DRIP assessment from Table 2, are described in detail in Table 4.

\section{Discussion}

The digital readiness index for ports (DRIP) embraces 5 dimensions and 38 related indicators (cf. Tables 1 and 2). As mentioned by Philipp et al. (2020b), these five dimensions (i.e. "Management", "Human Capital", "Functionality (IT)", "Technology" and "Information") were incorporated into the digital auditing tool, since the digital transformation of ports is not safeguarded by only using innovative technologies. It is more the interplay of management measures and employees' knowledge and skills, as well as functional IT processes and systems with these digital technologies that ensures a sustainable development towards a smart port. Moreover, it is essential to guarantee a comprehensive information procurement regarding current digitalisation trends. Through this, port representatives can inform themselves and receive awareness of achievable added value that comes from a sustainable digital development. Furthermore, this ensures the proper identification of adequate actions and investments during the strategic decision-making process.

The indicated weighting factors in the DRIP model represent the importance of each dimension, which had been determined during expert interviews with project experts. The distribution of the importance or weight, respectively, between the dimensions in the presented digital readiness assessment model may represent a subject for future discussions. The experts of the Connect2SmallPorts project emphasised that this weighting factors might be subjective, but undoubtable a weighting of the dimensions needs to be incorporated in the indexing procedure, as the five dimensions cannot be regarded as equal important. Against this, in the current DRIP model all indicators are equally weighted in each dimension, which may represent another subject of discussions. However, all PPIs and further chosen indicators are gathered in form of qualitative data according to a six-item Likert-scale, which at the same time secures the practical application friendliness for a potential digital readiness self-assessment. Nevertheless, the weighting of the different dimensions and indicators might be adjusted in other situations by respecting the regional peculiarities, economic perspectives and stakeholders' interests.

Another potential subject for discussion could be seen the assessment of the PPI "IT Capability" via the seven subindicators in Table 3. In this context it might be argued that especially "IT Capabilities" represent an essential-if not the most important-source for a sustainable development towards a smart port. Hence, possibly these sub-indicators 
should receive more weight through the incorporation as full indicators in the overall DRIP model, which is equal to a direct integration into the tool next to the 38 already fully acknowledged indicators. However, in this present study they had been separated, since they all refer to the same holistic indicator "IT Capabilities", which was weighted with the same importance as the PPIs "IT Knowledge \& Skills" and "IT Training \& Education Opportunities" in the dimension "Human Capital".

By taking into account the presented strategic graduation towards a smart port development, which is showcased in Table 4, it can be further noted that the previously applied digital readiness index for ports is extended by a component of a maturity model. Accordingly, building upon the benchmarking and indexing of the ports via the DRIP, the current strategic positioning of the ports based on the respective digital performance that is characteristic for each of the different digital port types becomes obvious. As emphasized in Table 4, through this, the respective strategic recommendations for a sustainable development towards a smart port can be derived in accordance to each port classification. Accordingly, for both, Valencia and Klaipeda port that can be classified as "Developer ports", it might be strategically suggested to use the achieved high digitalisation degree for the creation of a competitive advantage and to maintain the competitive advantage by targeting on further and broader sustainable integration of the hinterland and thus, to extended the network of stakeholders by exceeding the hinterland. Moreover, new businesses should be generated, whereby ecosystem partnerships should expand. Regarding the two German ports (i.e. Stralsund and Wismar), that both can be categorised as "Adopter ports", it might be suggested to prioritise the customer relationships depending on own processes and service structure. Furthermore, strategic and other decisions should be driven by analytics, whereby environmental changes must be stronger and more thoroughly taken into account during decision-making process. Another strategic goal should be seen in the identification of new business opportunities. Concerning the Swedish port Karlskrona that is evaluated as a "Monitor port", it can be suggested to focus and improve the adaptive capacities. Especially the capabilities and knowledge of the employees on all hierarchical levels should be increased, whereby the outsourcing strategy for the acquisition of digital expertise represents a suitable alternative in the frame of the overall digitalisation strategy. Finally, Karlskrona port should try to move from an observer role to a more pro-active one.

\section{Conclusions}

Port performance measurement has a long-standing history. Nevertheless, existing PPI-concepts in theory and practice mainly focus on operational performance measurement in container ports. Hence, next to the obvious target-group limitation, there exist a lack of concepts and models for measuring the digital performance of ports. As the research revealed, the developed DRIP concept by Philipp et al. (2020b), which was so far only on a theoretical basis proposed, but now, in this study practically applied for the first time, represents a suitable and appropriate tool for auditing the digital performance of ports.

By taking into account the presented strategic graduation model towards a smart port development, it can be concluded that in the present study the previously applied DRIP concept became a maturity model. Furthermore, it can be concluded that through the indexing results of the investigated ports (i.e. DRIP score), which were generated by the application of the digital readiness index for ports, the current strategic digital positioning of the seaports became identifiable. Moreover, this ensured that the respective strategic direction (incl. strategic recommendations) for a sustainable development towards a smart port could be derived-in respect to the individual digital port classification.

Accordingly, through the presented and conceptualised port maturity model in this study that incorporates the DRIP concept from Philipp et al. (2020b) and the fitting strategic graduation matrix towards a smart port development, practitioners-i.e. especially port representatives like port authorities or operators, respectively - as well as researchers are able to assess the digital performance and readiness of ports, to identify the current strategic positing of ports in the digital context, to categorise the ports according their digital maturity status and to derive concrete digital strategic actions. Overall, through this, the roadmap for the digital transformation of ports towards smart port development was clearly stated by the definition of respective strategies in respect to the different digital port classifications. With other words, the developed maturity model can assist port authorities and operators as well as policy makers and other portrelated stakeholders during decision-making, and is able to support the identification and definition of an efficient and effective strategic direction for setting up the roadmap for the digital transformation of the port. However, due to the lack of comparable research studies a general methodological limitation is apparent.

Additionally, through the incorporation of a growing number of ports in the frame of the future research activities and through the incorporation of PPIs that target to measure the operational performance of ports, it will be possible to investigate the potential relationship between the digital and operational performance of ports. Moreover, as an extra concluding remark for future research activities, it was also noticeable in this study that all investigated ports show low digital readiness in case of some digital technologies-e.g. "Blockchain (incl. Smart Contracts)" and "Arti- 
ficial Intelligence (AI)". Despite the fact that there already exist research studies that targeted these topics (e.g. Henesey and Philipp 2019; Philipp et al. 2019b, 2019c; etc.), future research activities should stronger focus on proposing respective use cases, since the results of the present study showcased that so far these technologies have not or hardly been implemented and used in ports.

Acknowledgements The European Regional Development Fund (INTERREG VA South Baltic programme) within the project "Connect2SmallPorts" has supported this research article.

Funding The European Regional Development Fund (INTERREG VA South Baltic programme) within the project "Connect2SmallPorts" has supported this research article.

Funding Open Access funding provided by Projekt DEAL.

Conflict of interest R. Philipp declares that he has no competing interests.

Open Access This article is licensed under a Creative Commons Attribution 4.0 International License, which permits use, sharing, adaptation, distribution and reproduction in any medium or format, as long as you give appropriate credit to the original author(s) and the source, provide a link to the Creative Commons licence, and indicate if changes were made. The images or other third party material in this article are included in the article's Creative Commons licence, unless indicated otherwise in a credit line to the material. If material is not included in the article's Creative Commons licence and your intended use is not permitted by statutory regulation or exceeds the permitted use, you will need to obtain permission directly from the copyright holder. To view a copy of this licence, visit http://creativecommons.org/licenses/by/4. $0 \%$.

\section{References}

BBVA Research Homepage https://www.bbvaresearch.com/en/ publicaciones/digix-2018-a-multidimensional-index-ofdigitization/. Accessed 26 Jan 2020

Cullinane K, Song DW, Wang T (2005) The application of mathematical programming approaches to estimating container port production efficiency. J Prod Analysis 24(1):73-92

Decker J, Blaschczok J (2018) Digital readiness analysis (DiREA) of logistics service providers. Proceedings theory and applications in the knowledge economy, Poland, 465-477

Deloitte (2017) Smart ports, point of view. https://www2.deloitte.com/ content/dam/Deloitte/nl/Documents/energy-resources/deloittenl-er-port-services-smart-ports.pdf. Accessed 26 Jan 2020

Diekmann A (2007) Empirische Sozialforschung: Grundlagen, Methoden, Anwendungen, 18th edn. Rowohlt, Hamburg

Döring N, Bortz J (2016) Forschungsmethoden und Evaluation. Springer, Wiesbaden

Douaioui K, Fri M, Mabrouki C, Semma E A (2018) Smart port: design and perspectives. In: 2018 4th International Conference on Logistics Operations Management (GOL). IEEE, Le Havre, pp 1-6. https://doi.org/10.1109/GOL.2018.8378099

Gardeitchik J, Buck W, van der Deijl A (2017) Move Forward: Step by step towards a digital port (Whitepaper). PortForward-Digital solutions by Port of Rotterdam, Rotterdam

Gill M, VanBoskirk S (2016) The digital maturity model 4.0. Benchmarks: digital transformation playbook

Ha MH, Yang Z, Lam JSL (2019) Port performance in container transport logistics: a multi-stakeholder perspective. Transp Policy $73: 25-40$
Henesey L, Philipp R (2019) Evaluating LNG bunkering automation technology. In: Casaca (ed) 2019 World of Shipping Portugal An International Research Conference on Maritime Affairs, Carcavelos (https://www.researchgate.net/publication/336899809. Accessed 26 January 2020)

Horvat D, Stahlecker T, Zenker A, Lerch C, Mladineo M (2018) A conceptual approach to analysing manufacturing companies' profiles concerning Industry 4.0 in emerging economies: Paper ID: 1213. Procedia Manuf 17:419-426

Kvale S (2008) Doing interviews. SAGE, Hoboken

de Langen P, Nidjam M, van der Horst M (2007) New indicators to measure port performance. J Marit Res 4(1):23-36

Lloyd (2019) One hundred ports 2019. https://lloydslist. maritimeintelligence.informa.com/one-hundred-container-ports2019. Accessed 26 Jan 2020

Miles MB, Huberman AM (1984) Qualitative data analysis: A sourcebook of new methods. In: Qualitative data analysis: a sourcebook of new methods. SAGE, Hoboken

O'Leary Z (2017) The essential guide to doing your research project. SAGE, Hoboken

Philipp R, Gerlitz L, Moldabekova A (2020b) Small and medium-sized seaports on the digital track: tracing digitalisation across the south baltic region by innovative auditing procedures. In: Kabashkin I, Yatskiv I, Prentkovskis O (eds) Reliability and statistics in transportation and communication. Relstat 2019. Lecture notes in networks and systems, vol 117. Springer, Cham, pp 351-362 https:// doi.org/10.1007/978-3-030-44610-9_35

Philipp R, Gerlitz L, Prause G (2018) Regional Häfen auf Digitalisierungskurs: Intelligentes Wachstum und nachhaltige Wertschöpfung entlang der kleinen und mittel-großen Häfen des Ostseeraumes. In: Cleve A, Wißotzki (eds) Proceedings of WiWiTa 2018 Conference Wismar, pp 77-86. ISBN 978-3-942100-58-8

Philipp R, Ozarska A, Prause G (2019a) Sustainable electronic product development in the baltic sea region: a regional gap analysis of lab testing services. Environ Clim Technol 23(3):85-100. https://doi. org/10.2478/rtuect-2019-0081

Philipp R, Prause G, Gerlitz L (2019c) Blockchain and smart contracts for entrepreneurial collaboration in maritime supply chains. Transport Telecommun 20(4):365-378. https://doi.org/10.2478/ ttj-2019-0030

Philipp R, Prause G, Meyer C (2020a) Blue growth potential in south Baltic sea region. Transport Telecommun J 21(1):69-83. https:// doi.org/10.2478/ttj-2020-0006

Philipp R, Gerlitz L, Prause G (2019b) Smart contracts for entrepreneurial collaboration in logistics networks. 11th international scientific conference "new challenges of economic and business development-2019: incentives for sustainable economic growth", at: university of Latvia-Riga. https://www. researchgate.net/publication/336316066. Accessed 26 Jan 2020

Porter ME (1985) Competitive advantage: creating and sustaining superior performance. Nova Science Publishers, New York

Rajnai Z, Kocsis I (2018) Assessing industry 4.0 readiness of enterprises. In: 2018 IEEE 16th World Symposium on Applied Machine Intelligence and Informatics (SAMI). IEEE, Kosice, pp 225-230. https://doi.org/10.1109/SAMI.2018.8324844

Roland Berger Homepage (2020) https://www.rolandberger.com/ en/Publications/Industry-4.0-\%E2\% $80 \% 93$-the-new-industrialrevolution.html. Accessed 26 Jan 2020

Schnell R, Hill PB, Esser E (2004) Methoden der empirischen Sozialforschung

Stake RE (1995) The art of case study research. SAGE, Hoboken

Talley WK (1994) Performance indicators and port performance evaluation. Logist Transp Rev 30(4):339

Talley WK (2006) Port performance: an economics perspective. Res Transp Econ 17:499-516 
Tongzon JL (1995) Determinants of port performance and efficiency. Transp Res Part A Policy Pract 29(3):245-252

UNCTAD (1976) Port performance indicators, united nations conference on trade and development. UNCTAD, New York

Wang TF, Song DW, Cullinane K (2003) Container port production efficiency: a comparative study of DEA and FDH approaches. J East Asia Soc Transp Stud 5(10):698-713

World Economic Forum (2016) http://reports.weforum.org/globalinformation-technology-report-2016/networked-readiness-index/. Accessed 26 Jan 2020
Yang Y, Zhong M, Yao H, Yu F, Fu X, Postolache O (2018) Internet of things for smart ports: technologies and challenges. IEEE Instrum Meas Mag 21(1):34-43

Yin RK (2017) Case study research and applications: design and methods. SAGE, Hoboken 